\title{
ÉPOCAS, COHORTES Y GENERACIONES DE CHILENOS/AS: EXPLORACIÓN EN TORNO A LOS GRUPOS SOCIOEPOCALES
}

\author{
MANuel CANALES CeróN* \\ FELIPE GHIARDO SOTO**
}

\begin{abstract}
RESUMEN
El artículo analiza la relación entre distintas cohortes etarias y un conjunto de señales que caracterizan las diferentes décadas que cubre el proceso de modernización en Chile. A partir del análisis del grado en que las cohortes se reconocen en una serie de ámbitos en cada una de las décadas y su correspondencia con elementos ideológicos, se plantea la posibilidad de asumir como generaciones a las cohortes que participan del estudio y se discuten luego las posibilidades y límites que presenta el componente generacional como analizador social.
\end{abstract}

PALABRAS CLAVE: COHORTES, ÉPOCAS, GENERACIONES

\footnotetext{
* Académico Departamento de Sociología de la Universidad de Chile. E-Mail: mcanales@uchile.cl.

** Licenciado en sociología. E-Mail: felipe @ cidpa.cl.
} 


\title{
ÉPOCAS, COORTES E GERAÇÕES DE CHILENOS/AS: EXPLORAÇÃO SOBRE GRUPOS SOCIOEPOCAIS
}

\begin{abstract}
RESUMO
$\mathrm{O}$ artigo analisa a relação entre diferentes coortes etárias e um conjunto de sinais que caracterizam as distintas décadas que cobrem o processo de modernização no Chile. A partir da análise do grau em que as distintas coortes se reconhecem em uma série de âmbitos em cada uma das décadas, bem como sua correspondência com elementos ideológicos, estabelece-se a possibilidade de se considerar como gerações as coortes que participam do estudo, discutindo-se as possibilidades e limites do componente geracional como analisador social.
\end{abstract}

PALAVRAS CHAVE: COORTES, ÉPOCAS, GERAÇÕES

\section{TIME PERIODS, COHORT AND GENERATIONS OF CHILEANS: EXPLORING AROUND THE DIFFERENT GROUPS OF SOCIAL TIME PERIODS}

\begin{abstract}
The article analyzes the relationship between different age cohorts and a set of signals characterizing the decades that covers the process of modernization in Chile. By analyzing the extent to which the different cohorts are recognized in a number of areas in each of the decades and their correspondence with ideological elements raises the possibility of taking over as generations cohort participating in the study and then discusses the possibilities and limits encountered by the generational component as social analyzer.
\end{abstract}

KEY WORDS: COHORT, TIME PERIODS, GENERATIONS 


\section{Preguntas y CONCEPTOS}

\section{Las preguntas}

SE SABE DE LOS grupos socioeconómicos y su conexión con ingresos. Y se sabe que esta conexión es lógica e ideológica: se expresa tanto en niveles o volúmenes de consumo como en tipos o estilos de consumo. Se ha estudiado también a los grupos etarios o coetáneos para identificar rasgos específicamente asociados a las «fases de la biografía» que los distintos individuos están cursando en un momento dado. Así, el campo de estudio de las edades, de la adolescencia, la juventud, y últimamente, la vejez.

Este estudio busca analizar si es posible identificar grupos epocales, esto es, conjuntos de individuos que se reconozcan como contemporáneos a ciertas épocas o momentos de la vida social, conocido por vivencia directa o por resonancias culturales. La pregunta es si se pueden identificar conjuntos socioepocales en que se reconozcan los individuos de la población chilena, para ver, al mismo tiempo, cuáles son las variables que determinan la formación de estos grupos — si influyen, por ejemplo, los niveles de educación, los ingresos, el género, la edad y el territorio-.

\section{Los conceptos}

\section{a) Acerca de los grupos socioepocales}

Un grupo socioepocal puede definirse como un conjunto de individuos que se reconocen marcados o influidos por unos mismos tiempos o fases de la vida social. Un tiempo o fase de la vida social puede ser concebido como un paisaje/pasaje histórico. Esto es, como una forma de «convivencia» propia de un tiempo o era específico de una sociedad determinada. La noción de época es elástica, y lo mismo puede indicar microépocas como eras históricas en el sentido fuerte. Ambas nociones conviven en el sentido común, son épocas; por ejemplo, Antigüedad, Edad Media, etcétera; lo mismo que circula como tal la noción asociada a «los sesenta» $\mathrm{o}$ «los 80 » e incluso, por extensión, se le puede utilizar para indicar una estación o fase anual. Figurativamente se le puede utilizar también para señalar un corte arbitrario en la temporalidad de un proceso cualquiera, como hacen, por ejemplo, las revistas que distinguen «primeras» $\mathrm{y}$ «segundas» épocas. 
Lo que tienen de común todas estas nociones, bajo su diversidad evidente, es la alusión a la temporalidad o fases en una secuencia cronológica; esto es, a la cuestión del tiempo en que está organizada, como un proceso, la vida social. Es sin más la cuestión de la historicidad de la vida social, de modo que, aunque continua en el tiempo físico, es discontinua en el registro factual y cultural de su propio devenir. Cada época o tiempo social traería su propia impronta sobre los individuos. Por lo tanto, un grupo epocal está formado por los hijos de esa época. Pueden serlo, en principio, en un sentido «biológico»-en el sentido que se trata de un individuo nacido o criado biológicamente en esa época- o en el sentido noológico — en el sentido que se trata de un sujeto que se adjunta ideológicamente a dicha epocalidad-.

\section{b) Contemporáneos, coetáneos y generaciones}

Puede distinguirse, al menos conceptualmente, ${ }^{1}$ entre grupos de edad y grupos generacionales. La distinción resulta de la oposición de dos pares conceptuales: el par diacronía-sincronía, y el par biografía (de individuos) e historia (de la sociedad).

\begin{tabular}{|l|c|c|}
\hline & Diacronía & Sincronía \\
\hline Diacronía (biográfica) & & Grupos de edad \\
\hline Sincronía (social) & Generaciones & \\
\hline
\end{tabular}

Los grupos de edad marcan la diacronía de la sincronía: múltiples relojes biográficos, o fases de la vida, en un único tiempo social, un mismo presente. Los grupos generacionales, por su parte, marcan la sincronía en una diacronía: en las mismas fases biográficas, los sucesivos pasajes de una historia.

\section{EL INSTRUMENTO DE INVESTIGACIÓN}

Para medir lo que aquí se define como el «efecto de influencia epocal» en cada individuo, se construyó un instrumento que puede describirse

1 Asunto bien distinto es si esta distinción conceptual se verifica empíricamente. Veremos que precisamente la superposición de las dos configuraciones es el dato básico del estudio: las generaciones se corresponden con los grupos de edad; y a la inversa también vale: cada grupo de edad se manifiesta efectivamente como una «generación» histórica, en el sentido aquí conceptuado. 
como una paleta de veinticuatro imágenes de época construidas como textos que hacen el boceto verbal de una fase social respecto a un conjunto de líneas temáticas. ${ }^{2}$ Distinguimos tres fases y ocho líneas temáticas.

\section{Fases o tiempos}

Como referentes de época se usó un criterio simple basado en la noción de décadas. Se pregunta por «los años 50», «los años 80», «los años $90 »$. El corte es naturalmente debatible y arbitrario, aunque razonado. En principio, todos lo serían. Este estudio no parte de una hipótesis dura o fuerte sobre «épocas» ya definidas. Asume una posición menos exigente, pues nada indica que solo exista epocalidad y generaciones en situaciones como las que se indican para las «grandes» generaciones en la historia - como en la historia, a su vez legendaria, de la literatura - ${ }^{3}$ En nuestro caso, nos basta la continuidad histórica o procesal, cortada en al menos tres momentos, para tener una visión de aquella secuencia o continuo histórico que sí se puede dar por cierto.

En ese sentido, los años cincuenta tienen el anclaje en la última fase de una tradición que se va retirando, y la primera de una época o proceso de cambios que viene llegando y fuerte. «Los setenta y los ochenta» son una segunda fase, esta vez de penetración profunda de esos cambios y de constitución de la nueva realidad. Son los años de consolidación de la transformación chilena. Los «90 y dos mil» son la maduración y hasta la expansión desbordante de las tendencias de los 80, en un mismo sentido, pero en una escala e intensidad mayor. Es cuando los cambios, ya gestados, se aceleran. De ahí que ver la relación entre las diferentes cohortes y las citadas décadas permite, a su vez,

2 El recurso es evidentemente inexacto, en el sentido que sus reactivos necesariamente están trabajados en un registro «evocativo», por lo mismo tanto analógicos o por resonancias, como propiamente descriptivos. Lo que refiere cada ítem es en realidad una imagen que evoca el individuo. La inestabilidad lógica, en este caso, obedece a una razón técnica: fue el modo elegido, asumiendo el carácter exploratorio de este estudio. Su prueba fue la misma aplicación: los resultados son de alta consistencia tanto respecto al objeto (lo que los individuos marcan en cada época y ámbito) como a las variables externas o clasificatorias.

3 En la clásica distinción orteguiana de la «generación del 98» en España; o según el mismo Ortega y Gasset, la generación de fines del siglo XVIII en Europa (Napoleón, Balzac, Augusto Comte). 
una aproximación a los diferentes modos en que han sido vividos los procesos que marcan la «modernización» del Chile contemporáneo.

\section{Líneas temáticas}

Cada época se asume compuesta por un conjunto de ámbitos. El instrumento explora algunos de estos ámbitos como una forma de desmenuzar los aspectos que perfilan la epocalidad de los participantes del estudio. Las líneas temáticas fueron ocho e incluyen: i) Tecnologías domésticas o cotidianas; ii) Estilos de vida familiar; iii) Pautas y niveles de consumo; iv) Religión; v) Sexualidad; vi) Política; vii) Trabajo y empleo; viii) Mundo.

\section{III. ÉPOCAS Y COHORTES: LAS FORMAS DE LA EPOCALIDAD}

\section{Impacto por ámbito y época}

a) Por ámbitos

De acuerdo a los resultados, las líneas temáticas marcan desigualmente, pero de modo estable y consistente, a través de las épocas. El componente que más marca es la tecnología doméstica. Como se verá más adelante, es el ámbito que más parece facilitar la integración de las generaciones a las sucesivas épocas. Le siguen los estilos de vida y de consumo familiar, que también hacen de bisagra para el acople de las distintas cohortes a las distintas épocas.

Sexualidad, religión, política y empleo tienen comportamientos diferenciados según sujetos y según épocas. Traen su propia lógica que analizaremos con los datos precisos, sobre todo la política, que tiene un comportamiento todavía más específico. $\mathrm{Y}$ al final, los sucesos del mundo, que nunca marcan. 
GRÁFICO 1: IMPACTO EPOCAL SEGÚN ÁMBITO

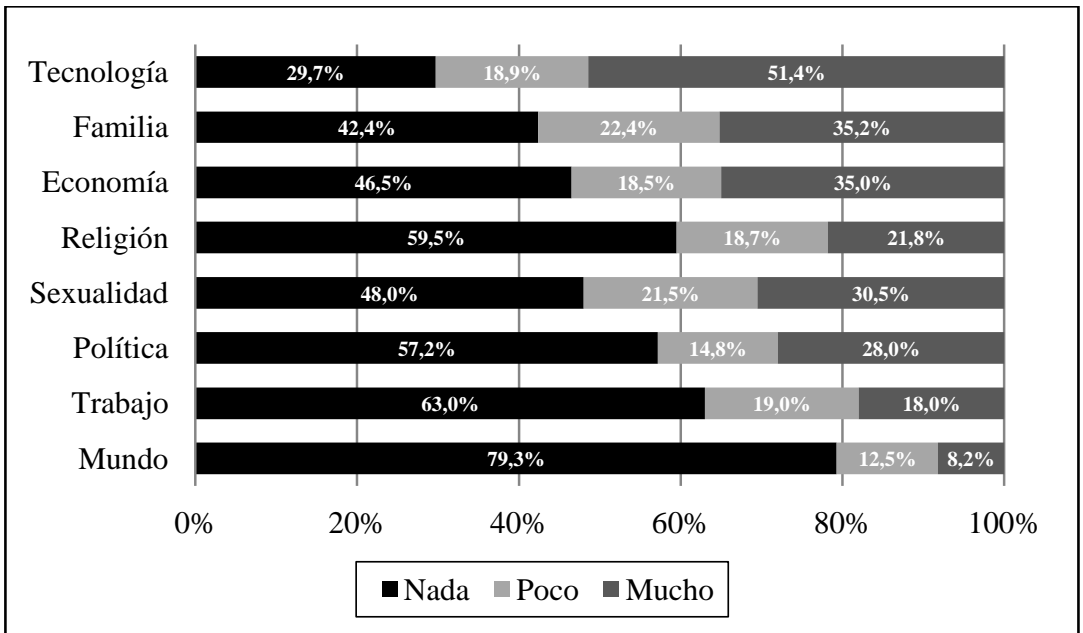

Fuente: Épocas y generaciones de chilenos. Fundación Visión Humana, Santiago, 2011.

\section{b) Por épocas}

Si se compara entre épocas, se descubre que, de todas, es la época actual la que marca al mayor conjunto de entrevistados. Lo contrario ocurre con la década más antigua, que es la que tiene la huella más débil en el conjunto. Las décadas intermedias marcan entre ambos extremos.

La comparación por cohorte empieza a revelar lo que hay tras estas diferencias. En la década más antigua solo marcan los mayores; mientras que la década más actual es la única que reúne a todas las cohortes. Ambas tendencias tienen una misma lógica: muestran la diferencia entre un presente común a los distintos grupos de edad y unas décadas pasadas que son imposibles de anclar en referentes concretos para quienes no las vivieron.

Un segundo análisis, esta vez de conglomerados, confirma la forma y revela su base. Al agrupar los casos de acuerdo a su grado de identificación con la época, lo que aquí se define como su epocalidad, empieza ya a resaltar que tras lo continuo puede haber un orden fuerte que hace que ciertos individuos marquen en una época mientras otros marcan en otra, y recíprocamente. Esto es, que están ordenadamente diferenciados. El análisis del perfil de los conglomerados revela su 
base: lo que organiza el cuadro es la edad. Solo la edad tiene, respecto a la variable epocal, una relación consistente y fuerte, además de ordenada. Su consistencia no la alcanzan ni el sexo, ni la escolaridad ni el nivel socioeconómico.

GRÁFICO 2: ÍNDICE EPOCAL POR ÉPOCA. COMPARACIÓN SEGÚN COHORTES

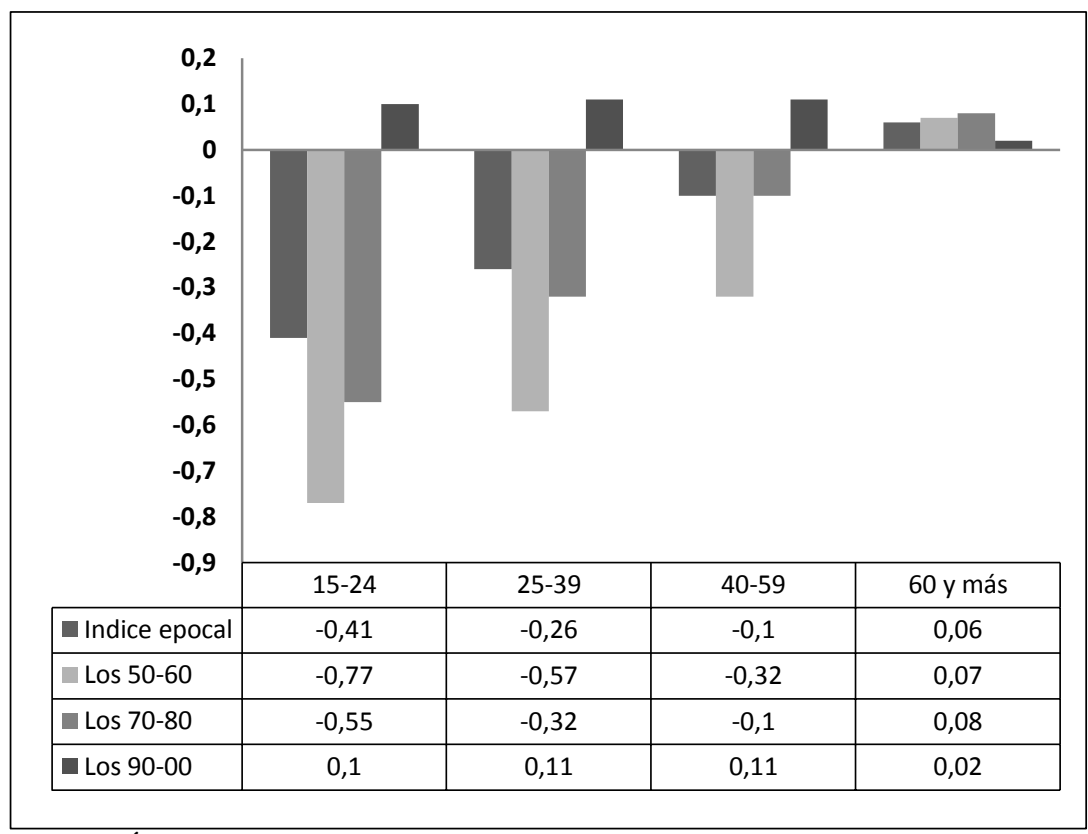

Fuente: Épocas y generaciones de chilenos. Fundación Visión Humana, Santiago, 2011.

De ahí puede empezar a colegirse ya una continuidad etariogeneracional. Primero porque, en lo general, a mayor edad, mayor sensibilidad al conjunto de indicadores de pertenencia de época utilizados. Gran parte de los casos que forman el conglomerado que presenta mayor identificación con el conjunto de la época son mayores y adultos, justamente lo inverso a lo que ocurre con los más jóvenes. Y, segundo, porque los grupos difieren no solo en más o menos de influencia epocal en general respecto al instrumento, sino que también lo hacen de modo que algunos marcan o reconocen estar influidos por ciertas épocas y otros por otras, y así también por ámbitos. Los mayores - 60 años y más - son la cohorte con mayor epocalidad y la única 
que marca en todas las épocas y en sus diferentes ámbitos, que es exactamente lo contrario de lo que ocurre con los jóvenes.

GRÁFICO 3: CONGLOMERADOS EPOCALES. COMPOSICIÓN SEGÚN COHORTES

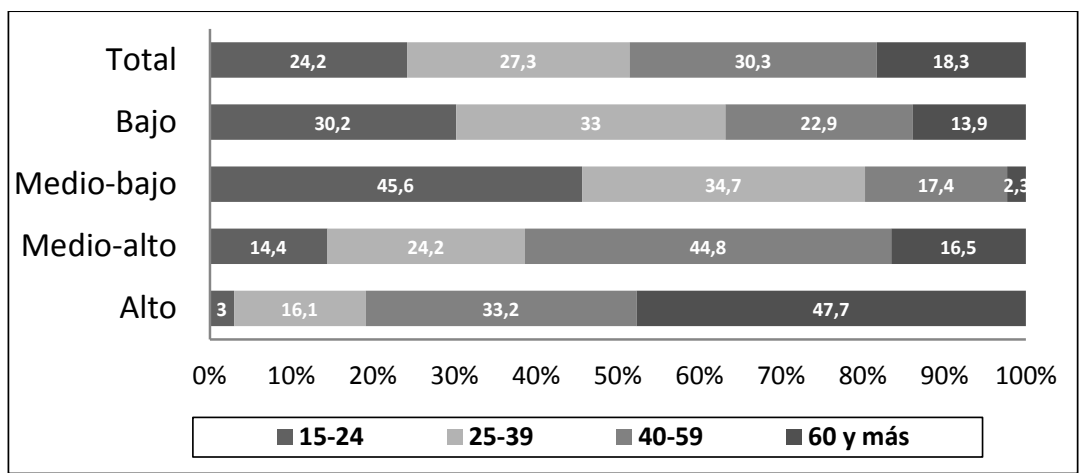

Fuente: Épocas y generaciones de chilenos. Fundación Visión Humana, Santiago, 2011.

El estudio exploró también el valor que atribuyen los individuos a las diferentes épocas. En este caso, la forma general es la misma que la de impacto: donde más se marca el impacto, es también donde más se marca en sentido positivo. Dicho de otro modo, los tiempos vividos como marca traen un signo de favorable o positividad básica, ${ }^{4} \mathrm{y}$ ambos siguen el orden de la edad.

Anticipamos así algo que nos seguirá hasta el final y que relaciona intrínsecamente edad con generación. Se revela que, en lo fundamental, épocas y edades vienen en algún lugar fusionados: las generaciones son la fusión etario-epocal. Edad y generación epocal vienen a ser lo mismo. Cabe decir, entonces, que las generaciones se determinan por la edad: los individuos tienden a marcar epocalmente como todos sus coetáneos. Pero también se demuestra que «las edades» son continuidades generacionales a través de las épocas: los individuos

4 Respecto a las valoraciones de época, cabe consignar dos regularidades notables, ambas relativas al contraste de «los 80» con «los 90». Se trataría de dos fases de la historia que se oponen fundamentalmente en lo que hace a la política y el trabajo. El contraste, en política, está en la valoración de época que se hace de la dictadura - todas las cohortes la repruebany la que se hace de la transición - todas las cohortes la aprueban-. Lo mismo en empleo: todos lo valoran positivamente en los 90 y negativamente en los 80. Política y empleo parecen, por lo tanto, condensar el paso de unos 80 duros a unos 90 que parecen más gratos. 
tienden a marcar según su cohorte en las diversas fases sociales/biográficas vividas. En ese sentido, cada grupo de edad no solo configura unas biografías sincronizadas en sus fases, sino también un acople compartido a una misma historia (unas épocas pasadas, vividas), y que va, a la vez, andando (una época presente y unas futuras). Ese fondo histórico común de la edad pocas veces se releva, y se le reduce a indicar la fase actual biográfica. En las conclusiones podremos retomar y desarrollar este aserto.

\section{Comparación por cohortes}

\section{a) Jóvenes (15 a 24 años)}

Los actualmente jóvenes marcan solamente en la última década y lo hacen de modo ambivalente: marcan alto en la actualidad tecnológica, en economía y consumo, y en sexualidad, pero bajo en mundo, religión, política y empleo. La diferencia sugiere que una particularidad de los jóvenes es que están en una etapa de actualización, en el sentido que «se activan» solo para esta época, y lo hacen progresivamente, desde los ámbitos más generales o «universales» (tecnología, consumo) a aquellos que requieren una inserción social propiamente de «adultos»: el trabajo, pero de algún modo también, como signo epocal, la política y el mundo. Con esto se adelanta algo que recorre todo el análisis y que irá explicando buena parte de las diferencias internas de cada cohorte en su acople a los distintos ámbitos y señas de época.

En el caso de los jóvenes, tecnología y sexualidad son ámbitos que solo marcan en esta época y la marcan más alto que todas las otras cohortes. Hacen juego así sexualidad con tecnología: los jóvenes se integran al mundo por estas vías. Pero hay una diferencia importante entre uno y otro. Todos los subconjuntos, desde los más hasta los menos acoplados a la época, se reconocen parte de la última era tecnológica. En la sexualidad, en cambio, el subconjunto que presenta el promedio epocal más bajo no alcanza a marcar. La sexualidad, de hecho, divide a la cohorte en dos grupos: uno mayoritario que se reconoce en la marca correspondiente, y otro grupo que no, acaso por un efecto etario que se produce porque el grupo «bajo» es el más joven. Primer ejemplo del «aún no» que define a esta edad.

La misma forma se revela en el caso de la política y el empleo. Aquí marcan positivo los grupos más altos, pero muy negativo el grupo más bajo, y al igual que en sexualidad, la tendencia se explica por 
la menor edad de este último grupo. Por uno y otro lado se configura, entonces, el efecto de la edad en los procesos de activación que encuentra su ejemplo más claro en el grupo más joven y de menor adherencia a la época, en su particularidad de ser el grupo que todavía-no se acopla a estos ámbitos del marco epocal actual, básicamente porque todavía no los vive desde dentro.

Con la religión sucede algo distinto o, quizá, lo inverso. Todos los conglomerados marcan negativo, incluso los de alta epocalidad, pero no por una integración que todavía-no se produce, o que podría estar en curso, como en política y trabajo, sino porque se trata de un ámbito en que la integración queda atrás y se aleja. Los jóvenes son los que nacieron a la salida o, derechamente, fuera de la cultura religiosa intensa tradicional, los que ya-no vivieron esa experiencia y están distantes de ella. En ese sentido son propiamente los primeros post-tradicionales de modo radical y total, los nacidos cuando la tradición ya ha caído en su eje basal. Más aún, esta es la primera generación que ya no se reconoce ni en su propia época religiosa. La religión es la puerta por la que «ya no se ingresa», signo acaso redundante o paradójico de una nueva religiosidad que, en comparación a las formas previas, como experiencia, precisamente es suave y difusa.

Un último punto a destacar se produce en lo que refiere a la valoración sobre la década. Aquí los datos se muestran consistentes con los del impacto: marcan fuerte en tecnología y en economía familiar, pero sobre todo la tecnología, que destaca por su altísima valoración positiva. Su valoración es fuerte en todos los grupos, desde los más a los menos acoplados a la época. En cambio, en economía y consumo marca positivo solo el grupo que se reconoce más marcado por la época —que representa a cerca de un $40 \%$ - La mayoría restante parece que no se reconoce del todo en esta época de consumismo, malls y publicidad, como si a una parte no terminara de seducirlo el «nuevo consumo» y desconfiara de su marca de abundancia, salvo ese porcentaje de adictos a la época. ${ }^{5}$

5 Este tema se podría retomar en posteriores estudios. Por lo pronto, la comparación entre grupos sugiere que las valoraciones más negativas se dan entre los más jóvenes, y más entre los hombres que entre las mujeres. También es importante la diferencia que introduce el territorio: la visión positiva es más frecuente en las metrópolis, y la negativa, en las provincias. Las variables socioeconómica y educacional marcan irregular o inestablemente: solo por abajo el grupo D se manifiesta polarmente en el juicio negativo. 


\section{b) Adultos-jóvenes (25 a 39 años)}

Los adultos-jóvenes tienen dos épocas básicas de referencia: los 70-80 y los 90-2000. De las dos, el vínculo más fuerte es con la segunda. Solamente un segmento menor de esta cohorte se reconoce marcado por la primera década, probablemente los de mayor edad. La debilidad de ese vínculo cubre todos los ámbitos, a excepción de la tecnología de los setenta, que aparece como la única puerta ancha de entrada a esa década. Con todo lo demás, los adultos-jóvenes guardan distancia, sobre todo con el empleo, la religión y la situación del mundo.

GRÁFICO 4: EPOCALIDAD EN ADULTOS-JÓVENES POR ÁMBITOS.

DÉCADAS «70-80»Y $\ll 90-2000 »$

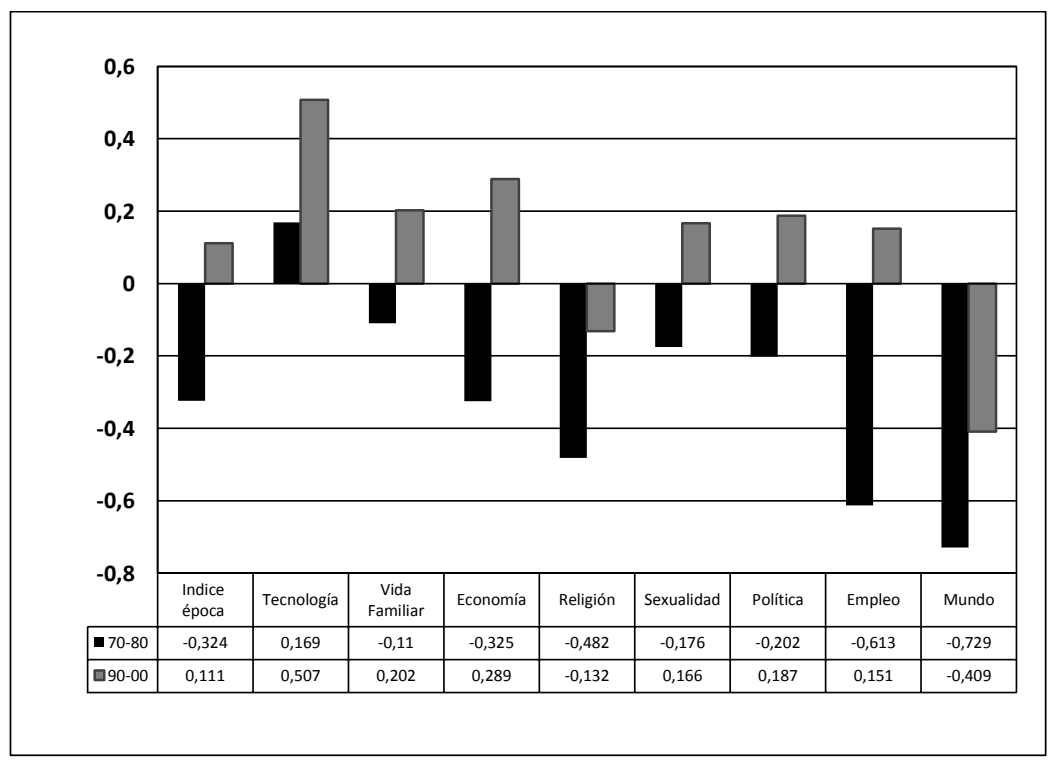

Fuente: Épocas y generaciones de chilenos. Fundación Visión Humana, Santiago, 2011.

Lo del empleo se entiende, porque en los setenta y ochenta eran los jóvenes recientemente ingresados, o aún ingresando, a la esfera adulta donde se encuentra el empleo. Lo de religión es más curioso: no marcan en los setenta, pero sí en los noventa, como si esta generación no hubiera alcanzado a conocer la época en que se anuncia el retroceso de la religión, pero sí la actual, en que se profundiza la individualización de la vida religiosa.

Al pasar a los noventa, el conjunto de la cohorte estrecha su relación con la época. Si en los setenta solo marcaba fuerte y variado el 
grupo de mayor epocalidad, ahora la cohorte en su conjunto pasa a marcar positivo en casi todos los ámbitos, con saltos notorios y destacables. Las únicas excepciones son el mundo y la religión, pero en general se puede sostener que los adultos-jóvenes están más dentro que fuera del rumbo que han tomado los cambios tecnológicos y culturales en su última fase histórica. También destaca el movimiento en política, empleo y sexualidad: en el paso de los setenta a los 90, la mayoría de los individuos de la cohorte parece haber experimentado un giro en relación a estos tres ámbitos.

Sólo una parte relativamente menor del conjunto mantuvo distancia y no siguió la tendencia general de sus coetáneos, justamente el grupo que clasifica a los adultos-jóvenes más alejados de la época. Para los otros dos — que en conjunto representan a más del 70\%—, el cambio de década fue un período de integración y activación social y epocal. Ambos presentan una pauta de integración análoga, pero que difieren en los ritmos o tiempos de inserción a los distintos ámbitos. La del grupo de mayor epocalidad fue más temprana. Ya en los setenta marcaba en una variedad de ámbitos, a excepción de religión, empleo y mundo y en los noventa marca en todo y con puntajes sobresalientes en política, empleo y sexualidad. La del segundo grupo es posterior. En los setenta permanece ajeno a todos los ámbitos que no fueran la tecnología - similar, en ese sentido, al comportamiento del grupo de baja epocalidad-, pero en los noventa pasa a marcar positivo en todas las dimensiones que definen la década, salvo en religión, en la que no entra, al punto de emparejarse ahora con el primer grupo.

Parte de la diferencia se explica por la condición socioeconómica y la educación - dos variables que correlacionan positivo con la integración-, pero el principal factor sigue siendo el etario. El grupo de mayor epocalidad marca en los setenta porque tiene, en promedio, más edad; por eso el segundo grupo, más joven, no marca en los setenta, pero con el paso a los noventa experimenta un giro y alcanza niveles altos en prácticamente todos los referentes de época. La duda queda en torno al grupo de menor adherencia: marca bajo para todas las épocas y en todos los ámbitos, con un comportamiento plano insensible a la edad, sin perfil, caso único de actor desconocido.

\section{c) Adultos (40 a 59 años)}

Los adultos marcan en distintas épocas, pero con mayor intensidad en los setenta y noventa. En los cincuenta no marcan fuerte en ningún 
ámbito, salvo el grupo que componen los adultos de alta epocalidad, que forman el tercio de esta cohorte que se reconoce en todos los ámbitos, salvo en dos: en las formas de trabajo de los 50-60 y en la era política de los Radicales, probablemente por ser, en aquellos años, todavía jóvenes, no integrados plenamente a estas dos esferas.

Para las décadas de los 70-80, la influencia de la época se hace más notoria y transversal en el conjunto de la cohorte. Es intensa la huella que trae la era de expansión del automóvil y los electrodomésticos en tecnología, y profunda también la marca que dejaron los años de dictadura. También destaca la marca que dejan los cambios en las estructuras familiares, las primeras fases de expansión de la sociedad de consumo y los primeros pasos de la liberación sexual, tres de los cambios culturales más determinantes de la segunda mitad del siglo XX.

Las mayores distancias se mantienen respecto a la situación del mundo, el empleo y la religión. La distancia respecto a la situación del mundo repite las tendencias de las cohortes anteriores. Lo que ocurre con la religión se comentará en seguida. Y en lo que respecta al empleo, se confirma el modelo que predice según la edad, en el sentido que se tarda en entrar o se demora la entrada por empleo más que otros ámbitos, que en este caso, como se verá, se trata de una distancia más bien relativa, que obedece a la lejanía que mantienen los grupos más alejados de esta década respecto a este ámbito de la «sociedad adulta».

Al pasar a «los 90» el vínculo de la cohorte con el período se intensifica. Aquí los adultos marcan fuerte, incluso más que en la década anterior, y lo hacen en todos los ámbitos —menos en la situación del mundo-. Ese es, quizás, uno de los puntos más destacables: el grado de conexión o acople a los tiempos actuales, que llega a ser incluso más fuerte que en la década anterior. No alcanzan la intensidad de las generaciones más jóvenes, pero el dato sugiere que los adultos se han arrimado sin problemas a la era de la computación e Internet, que han absorbido los cambios de régimen político y adaptado con relativa facilidad al paso de un tiempo en que el trabajo era estable y de por vida a otro que instala la movilidad laboral, la capacitación continua y la privatización de los sistemas de protección.

Lo otro interesante de esta cohorte es que expresa, quizás mejor que otras, las rupturas culturales que introduce el cambio epocal. Con el paso a los noventa para esta generación comienza a anunciarse la salida por las pautas culturales en sexualidad, al punto de que en esto se reúnen y forman grupo con los adultos mayores o tradicionales. Pero, por otra parte, es una generación adelantada en el cambio religioso, y allí 
hace conjunto con los más jóvenes. Esta situación que intercepta con otras generaciones, esta entelequia generacional, diría Mannheim (cf. Mannheim, 1993), doble entelequia en este caso, que superpone con la generación anterior y posterior, pone a los adultos entre las dos historias. Una, la religiosa, la ha llevado desde el inicio y hasta el final; la otra, de la sexualidad, la ha conocido desde el inicio, pero en la última fase su acople comienza a perder fuerza, como si ya en este plano no pudiera o no quisiera seguir los cambios y las eras. El cambio religioso se revela, de ese modo, perfectamente complementario al cambio en las culturas sexuales: al llegar a los noventa, el primero reúne a toda la población, salvo a los mayores de sesenta años; la sexualidad también parte en dos al conjunto, pero esta vez haciendo el corte en la edad mediana, para dejar a jóvenes y adultos-jóvenes por un lado, y adultos y mayores, por el otro. Todo indica, entonces, que se hizo más fácil ir cambiando en cultura religiosa que en cultura sexual; y lo mismo sugiere que el fondo mayor, o final, de la religión, era la sexualidad.

Tras esta dualidad que muestra la cohorte de los adultos lo que hay es la diferencia entre los adultos que van saliendo y los que van entrando a esta edad. Están los adultos de alta epocalidad, que marcan en todos los ámbitos y en todas las décadas - la excepción es siempre el mundo-, con un comportamiento que se acerca al de los mayores. Y están los adultos de epocalidad media, que no marcan nada en la década del cincuenta, que en los setenta se incorporan a la política, la tecnología y las formas culturales, pero todavía no al empleo, y que terminan marcando en todo recién en los noventa. Entre uno y otro la diferencia principal es la edad: el segundo grupo es como el primero, solo que aproximadamente diez años más joven. Por eso se diferencian en los setenta (para ellos, la más pasado), que es cuando se integra el primer grupo, y por eso se diferencian también en los noventa, que es cuando los mayores comienzan a quedar atrás en los cambios culturales. Por lo mismo, también, los que entran a esta edad al llegar los noventa alcanzan niveles de integración que en algunos ámbitos revierten las diferencias que se apreciaban en las décadas de los 70-80: en tecnología, economía, política y empleo, este grupo parece aun más acoplado que el grupo anterior, y eso confirma el modelo que predice según la edad. ${ }^{6}$

6 También ordena la variable socioeconómica, pero esta vez de modo distinto a lo visto en la cohorte anterior. Resulta que el grupo más alto esta vez es el más bajo socialmente, tendencia que se da parcialmente también con educación. La provincia vuelve a mostrar consistencia y se ubican en el grupo bajo. Las metrópolis y el norte, en los más altos. 


\section{d) Los mayores (60 y más años)}

Los mayores de sesenta traen el código complementario al juvenil. Son los que más marcan en general y los únicos que marcan en todas las épocas. Su alta conexión con el conjunto de la época estudiada los ubica como la generación que más puede testificar sobre las transformaciones en los diversos ámbitos, aunque ya en la última fase se nota una baja en la intensidad, con regularidades diferentes según el ámbito.

Se pueden distinguir tres modos en que se articula el par acople/desacople de los mayores a las distintas fases de esta «modernización sociocultural». La primera va desde la integración a la desintegración progresiva y se da en familia, economía y consumo, religión y sexualidad. En las tres primeras, la tendencia revela un rezago de los mayores que los deja atrás, pero no del todo fuera, como si en todos estos ámbitos que conectan más directamente con la vivencia de lo cotidiano, la tendencia fuera reconocerse en aquellas formas que más se acercan a sus primeras capas de experiencia, pero sin perder del todo la conexión con sus modalidades actuales. En la sexualidad, en cambio, el desfase se remarca al punto de que los mayores ya no participan de sus nuevos códigos. Lo hicieron en los tiempos en que hablar de sexualidad era tabú, y también, aunque en menor grado, en los años que despierta la liberación sexual; pero cuando la liberación llega pasa a una segunda etapa, se muestran descolocados o sin interés por integrarse.

Distinto es lo que ocurre en política y tecnología: la curva aquí es una parábola que parte relativamente baja en la primera década, sobre todo por la distancia con los gobiernos previos a Frei Montalva, se intensifica luego en el período que va de Frei y Allende hasta la dictadura, alcanza su máximo en este período y luego desciende en los años de la transición, sin llegar, eso sí, al extremo de retroceder a los niveles iniciales y menos perder todo vínculo con la actual era política. Se trata, más bien, de un retroceso parcial, igual que en tecnología, pero menos pronunciado. En tecnología, la trayectoria es similar al de la política, pero con una diferencia: también alcanza su máximo en los setenta, pero es más fuerte al principio que al final, como si los mayores no hubieran logrado seguir el ritmo que marca el paso desde la época de la televisión, los electrodomésticos y el teléfono residencial a la de los computadores y la conexión online. Aquí han quedado retrasados, incluso aquellos que lograron seguir de cerca la revolución tecnológica.

La tercera modalidad se da en el empleo y en la situación del mundo. En el caso del empleo, la tendencia muestra que el grueso de 
los ahora mayores no participó del todo activamente en aquella época lejana de industria incipiente y agricultura tradicional; que sí se integran con más fuerza en el período en que se expande la sociedad típicamente industrial, y que siguen esa misma dirección, pero aumentada, al expandirse las formas contemporáneas de trabajo. Eso es quizás lo que más llama la atención: que la marca más fuerte que deja el trabajo entre los mayores sea en la década más actual y no en los años setenta, que es, por cronología, el período en que debieran haber estado más plenamente activos. Habría que ver en detalle las razones que explican la tendencia. Quizá un grupo nunca se integró al mundo del trabajo estable y con protección que se usó para caracterizar los setenta. Quizá el ingreso fuerte y masivo de las mujeres al trabajo hace subir la marca del trabajo de las últimas dos décadas. Lo concreto es que la tendencia deja al trabajo como el único ámbito en que se pasa de la no integración a una integración cada vez más fuerte y positiva.

En el caso del mundo se repite la tendencia, aunque solo parcialmente. La resonancia que trae la situación más contemporánea del mundo es cada vez más importante, pero el mundo nunca llegó a marcar suficientemente fuerte a esta cohorte. Resulta interesante, en ese sentido, que los mayores se reconozcan más intensamente influidos por la situación actual del mundo que por la pasada, pese a la potencia histórica de períodos como la Segunda Guerra Mundial y la Guerra Fría.

Ahora bien, como se ha visto en las cohortes anteriores, entre los mayores se pueden distinguir grupos que han tenido grados y formas distintas de adherencia al amplio período que les ha tocado vivir. Se perfila así un grupo que concentra a los mayores con más epocalidad, compuesto principalmente por hombres de más edad y de ciudades metropolitanas, que es, de todos los conjuntos vistos en las diferentes cohortes, el que marca positivo en mayor extensión y variedad. En los cincuenta, se reconocen en todo, menos en mundo. Lo mismo en los setenta, con una notable marca en política tanto para el período Frei Montalva-Allende como para la dictadura, y que sigue intensa hasta los años de la Concertación. De hecho, probablemente sea esta alta politización su característica más notoria, pues en los demás ámbitos, a pesar de que sigue marcando positivo, no escapa a la tendencia a la baja en la última fase, en que comienza a marcar notablemente menos en tecnología, vida familiar y, sobre todo, en sexualidad.

A diferencia de este grupo, el de epocalidad media parece haber vivido el período desde más lejos. Apenas se reconocen marcados por la dictadura y los gobiernos de la Concertación, y en general no fueron 
activos en los años de los radicales y de Frei y Allende. En ese sentido, representa a los mayores despolitizados. Puede decirse que es el modo suave y recortado del anterior. Su conexión con las distintas épocas va, más bien, por las formas generales que traen la vida familiar, la tecnología y la economía, que son tres ámbitos que marcan en todas las décadas. En cambio, en política y en sexualidad no marcan nunca.

Por último, hay un grupo de mayores que ha permanecido todo el tiempo al margen. Son los mayores ausentes, un conjunto completamente plano respecto a las épocas y sus señas. Nunca fueron marcados por ninguna, salvo por la vida familiar de los años cincuenta, época de familias grandes y patriarcalismo tradicional. Quizá el único rasgo visible esté en su componente de clase, por la sobrepresencia del grupo $\mathrm{D}$ en el conglomerado. Pero, más allá de eso, lo importante de este grupo es que presenta de la forma quizás más aguda y profunda una tendencia común a la cohorte: su distanciamiento respecto a la última fase de la época, que puede venir desbalanceado y con intensidades variables según sea el ámbito, pero que en líneas generales resume el curso que han seguido los mayores en su relación con la época en estudio.

\section{ACTITUDES Y CREENCIAS DE GENERACIÓN}

Lo anterior permite identificar las cohortes de edad como soportes consistentes de una experiencia generacional compartida a través de una secuencia de momentos sociales coetáneamente con-vividos. En lo que viene se analiza su correspondencia con «ideologías de época», entendidas como actitudes básicas ante el tiempo biográfico y social, esto es, como actitudes ante la doble experiencia del tiempo que lleva lo humano: como individuos que van marcando sus fases biográficas; y como colectivo que va marcando sus fases sociales. Mediante este análisis se informa cómo los individuos de las distintas cohortesgeneraciones perciben aquella doble crónica que va contenida en la pregunta por la relación entre generaciones, mentalidades e historias.

\section{Las generaciones y la modernización}

a) Lo que el tiempo se llevó o lo perdido

Una primera pregunta remite a la noción de lo que se ha perdido con el paso del tiempo y los cambios de época. De todas, dos parecen las 
más sentidas: la tranquilidad y la vida comunitaria. Más abajo se encuentran el lamento por la falta de patria, de contacto con la naturale$z a$ y por el retroceso de la vida religiosa.

\section{GRÁFICO 5A: PRINCIPAL PÉRDIDA DE LA MODERNIDAD SEGÚN COHORTES}

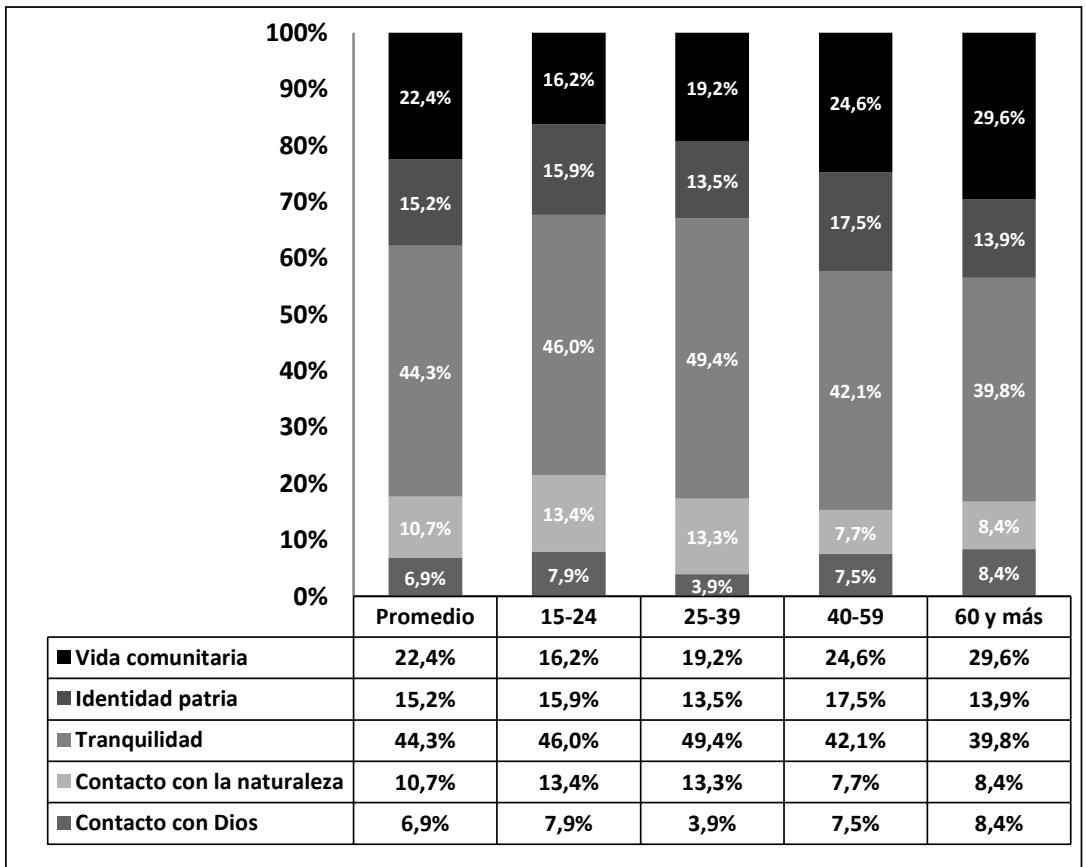

Fuente: Épocas y generaciones de chilenos. Fundación Visión Humana, Santiago, 2011.

No hay matices de género ni de educación. Sí cabe mencionar los que aparecen con la clase, el territorio y la generación. La diferencia de clase social muestra que lo que más lamentan los de abajo es la pérdida de comunidad, de aquel lazo protector que fuera, hasta los sesenta, la defensa y remanso popular en la inclemencia social; mientras el mayor lamento que tienen los de arriba es por la pérdida del contacto con la naturaleza y también remarcan la falta de Dios. ${ }^{7}$

7 Quizá sea en este último aspecto donde se ubica lo más interesante de este análisis: en el hecho de que la clase social en general libera de un conjunto de nostalgias, pero deja el espacio, entre ellas, solamente a las más «espirituosas». 
La comparación por territorio muestra que tanto en el norte minero como en las metrópolis se lamenta la pérdida de la calma y la tranquilidad, mientras los de provincia lamentan algo más la pérdida del vínculo, quizás porque ahí el lazo comunitario se conoció hasta más tarde, y hasta ahora, algo que en la metrópolis y el norte minero se diluyó antes.

\section{GRÁFICO 5B: PRINCIPAL PÉRDIDA DE LA MODERNIDAD SEGÚN GRUPOS SOCIOECONÓMICOS}

\begin{tabular}{|c|c|c|c|c|}
\hline \multicolumn{5}{|l|}{$100 \%$} \\
\hline $90 \%$ & $18,6 \%$ & \multirow{3}{*}{$21,0 \%$} & $18,2 \%$ & \multirow{2}{*}{$26,8 \%$} \\
\hline $80 \%$ & \multirow{2}{*}{$12,4 \%$} & & \multirow[b]{2}{*}{$17,4 \%$} & \\
\hline $70 \%$ & & & & \multirow{2}{*}{$14,4 \%$} \\
\hline $60 \%$ & \multirow{4}{*}{$40,0 \%$} & \multirow[t]{2}{*}{$15,5 \%$} & \multirow{4}{*}{$45,3 \%$} & \\
\hline $50 \%$ & & & & \multirow{4}{*}{$43,9 \%$} \\
\hline $40 \%$ & & \multirow{2}{*}{$16,8 \%$} & & \\
\hline $30 \%$ & & & & \\
\hline $20 \%$ & $17,2 \%$ & \multirow{2}{*}{$11,6 \%$} & \multirow[b]{2}{*}{$10,7 \%$} & \\
\hline \multirow{3}{*}{$\begin{array}{r}10 \% \\
0 \%\end{array}$} & \multirow[b]{2}{*}{$11,0 \%$} & & & \multirow{2}{*}{$\begin{array}{l}8,7 \% \\
5,6 \%\end{array}$} \\
\hline & & $4,8 \%$ & $8,1 \%$ & \\
\hline & ABC1 & C2 & C3 & D \\
\hline - Vida comunitaria & $18,6 \%$ & $21,0 \%$ & $18,2 \%$ & $26,8 \%$ \\
\hline - Identidad patria & $12,4 \%$ & $15,5 \%$ & $17,4 \%$ & $14,4 \%$ \\
\hline Tranquilidad & $40,0 \%$ & $16,8 \%$ & $45,3 \%$ & $43,9 \%$ \\
\hline Contacto con la naturaleza & $17,2 \%$ & $11,6 \%$ & $10,7 \%$ & $8,7 \%$ \\
\hline Contacto con Dios & $11,0 \%$ & $4,8 \%$ & $8,1 \%$ & $5,6 \%$ \\
\hline
\end{tabular}

Fuente: Épocas y generaciones de chilenos. Fundación Visión Humana, Santiago, 2011.

Pero es la comparación por generaciones lo que revela las diferencias más notorias. Aquí los mayores tienden a lamentar más que los demás la pérdida del vínculo comunitario, quizás porque la conocieron en su forma desarrollada, de un modo que las generaciones posteriores no alcanzaron. Los más jóvenes, por su parte, tienden a lamentar algo más que el resto la pérdida de la tranquilidad y la seguridad y algo más también la pérdida del contacto con la naturaleza. En ese sentido, son los más inquietos, o acaso habría que decir «inquietados» por la época, los que leen más directamente el signo desasosegado de los tiempos que vienen. 


\section{b) Lo logrado o los progresos}

La segunda pregunta remite a la evaluación que se hace a los progresos del período. Sus resultados muestran que las conquistas o logros que más reconocen las distintas cohortes son el crecimiento económico del país y los avances tecnológicos. Serían los dos ejes que verifican los avances del Chile de la segunda mitad del siglo XX. Algo se habría logrado también en el relato sobre las oportunidades, mientras el reconocimiento de los avances personales pareciera el más reducido, particularmente en lo que atañe a la libertad e igualdad.

Los contrastes generacionales destacan que son los adultos y los mayores quienes más remarcan el crecimiento económico, acaso porque lo han «construido»; pero no así los más jóvenes, que son los que menos lo reconocen como signo de avance, quizás porque han nacido ya adentrado el último y actual ciclo de la economía chilena.

En términos de clase, destaca el peso que tienen los avances tecnológicos en el imaginario del grupo mejor posicionado y la escasa importancia que le atribuyen a los avances en las libertades e igualdades sociales, quizá por su lejanía relativa con este orden de problemáticas. Los estratos más bajos y con menos años de escolaridad, en tanto, tienden a adoptar una valoración algo mayor, dentro de lo bajo, de la igualdad y la libertad de las personas, acaso por una memoria social de la servidumbre radical de hace medio siglo. Algo similar ocurre con este grupo respecto a la ya alta valoración del logro del crecimiento-país, por la sabida tendencia a la identificación con los logros nacionales que asumen los sectores de débil integración institucional, que la terminan remitiendo al plano de lo simbólico, de los espacios imaginarios y sin barreras de entrada que abre la congregación en medio de la segregación.

Con todo, tanto por los contrastes entre ámbitos como por las diferencias entre grupos etarios, socioeconómicos y territoriales, la sensación que queda es que la transición histórica que ha vivido la sociedad chilena termina con un balance incierto en sus logros. El país ha crecido mucho en lo económico, casi a la par que en las tecnologías; las oportunidades de los individuos solo algo, mientras que de la libertad y las igualdades, no se ha sabido mayormente. 


\section{Las generaciones y el tiempo: pasado, presente y futuro}

\section{a) Lecturas del pasado}

En paralelo del ámbito en que se anclan los cambios de la modernidad, está la evaluación sobre sus impactos. Aquí la pregunta específica es por la posición respecto al tiempo pasado. Los resultados dividen al conjunto en tres tercios: los que sienten nostalgia, los que ven al pasado como una fase ya superada, y los que lo ignoran y prefieren mirar siempre al futuro. Para cada gesto crónico hay su tercio respectivo.

GRÁFICO 6A: ACTITUD RESPECTO AL PASADO SEGÚN COHORTE

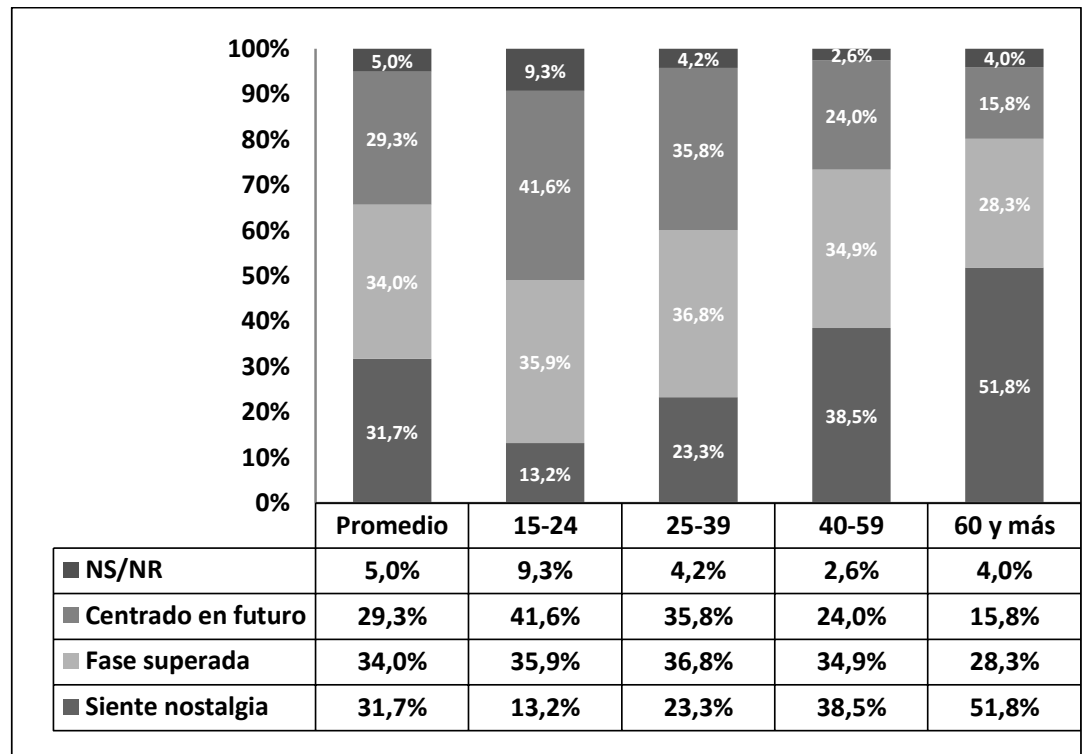

Fuente: Épocas y generaciones de chilenos. Fundación Visión Humana, Santiago, 2011.

Lo importante es que aquí se acentúan matices entre generaciones y clases que son decisivos - no así entre géneros-. Entre los jóvenes, la clase alta, los más educados, predomina la orientación al futuro: son proyecto. Su tiempo está por venir. Para los de abajo, más viejos y con menos escolaridad, en cambio, lo que queda es la nostalgia: los tiempos pasados siempre fueron mejores o, cuando menos, una fase superada que ya pasó, otra escena a la que le se le sobrevivió o perseveró. 
De todos, es la edad el factor que ordena las diferencias. Los adultos y sobre todo los mayores remarcan su nostalgia por los tiempos pasados. Entre los jóvenes, en cambio, no hay nostalgia, pero sí una fuerte orientación al futuro. ${ }^{8}$

\section{GRÁFICO 6B: ACTITUD RESPECTO AL PASADO SEGÚN GRUPOS SOCIOECONÓMICOS}

\begin{tabular}{|c|c|c|c|c|c|}
\hline $100 \%$ & $5,0 \%$ & $4,8 \%$ & $4,2 \%$ & \multirow{4}{*}{$35,6 \%$} & \multirow{4}{*}{\begin{tabular}{|l|}
$7,8 \%$ \\
$20,9 \%$ \\
\end{tabular}} \\
\hline $90 \%$ & \multirow{3}{*}{$29,3 \%$} & \multirow{3}{*}{$36,6 \%$} & \multirow{3}{*}{$34,4 \%$} & & \\
\hline $80 \%$ & & & & & \\
\hline 70\% & & & & & \\
\hline $60 \%$ & \multirow{3}{*}{$34,0 \%$} & \multirow{4}{*}{$40,7 \%$} & \multirow{4}{*}{$36,3 \%$} & \multirow{3}{*}{$31,9 \%$} & \multirow{3}{*}{$34,1 \%$} \\
\hline $50 \%$ & & & & & \\
\hline $40 \%$ & & & & & \\
\hline $30 \%$ & \multirow{3}{*}{$31,7 \%$} & & & & \\
\hline $20 \%$ & & & \multirow[b]{2}{*}{$25,1 \%$} & \multirow{2}{*}{$30,5 \%$} & $37,2 \%$ \\
\hline $10 \%$ & & $17,9 \%$ & & & \\
\hline $0 \%$ & Promedio & ABC1 & C2 & C3 & D \\
\hline NS/NR & $5,0 \%$ & $4,8 \%$ & $4,2 \%$ & $2,0 \%$ & $7,8 \%$ \\
\hline Centrado en futuro & $29,3 \%$ & $36,6 \%$ & $34,4 \%$ & $35,6 \%$ & $20,9 \%$ \\
\hline Fase superada & $34,0 \%$ & $40,7 \%$ & $36,3 \%$ & $31,9 \%$ & $34,1 \%$ \\
\hline Siente nostalgia & $31,7 \%$ & $17,9 \%$ & $25,1 \%$ & $30,5 \%$ & $37,2 \%$ \\
\hline
\end{tabular}

Fuente: Épocas y generaciones de chilenos. Fundación Visión Humana, Santiago, 2011.

\section{b) El tiempo y sus pronósticos}

Una forma complementaria en la relación con el tiempo son las expectativas respecto al futuro. Llama la atención, en este caso, el amplio optimismo que caracteriza al conjunto: todas las cohortes se muestran optimistas respecto a lo que vendrá, desde los más jóvenes hasta los adultos y mayores. No obstante, la comparación entre cohortes muestra que la incertidumbre y sensación de riesgos que invade a los mayores es algo más fuerte que entre las dos cohortes más jóvenes. El

8 Queda pendiente, de todos modos, la pregunta por cuál sería, en su momento, la actitud de los hoy adultos y mayores frente al tiempo. ¿Sería también de futuro? 
análisis según clase, por su parte, muestra una concentración de la incertidumbre en los sectores peor posicionados, como si la fragilidad económica del presente se tradujera en fragilidad subjetiva de cara a lo por venir, algo que en su cruce afecta también a los adultos y adultosjóvenes de estos mismos sectores — no así a los más jóvenes-, aunque sin que alcance a separarlos del optimismo mayoritario que muestran sus respectivas generaciones.

\section{c) La edad actual, el presente}

El modo en que cada cual vive su actual edad es otra seña complementaria. Remite a la vivencia del tiempo presente en su doble registro de personal y colectivo o sociohistórico. Aquí lo primero es que se parte del reconocimiento de una diferencia entre las edades o etapas de la vida: pocos creen que todas sean iguales, aunque entre los ya adultos se amplía más que en los otros grupos la tendencia a pensar que sí los son, quizá como intento de reafirmación frente al paso real del tiempo.

\section{GRÁFICO 7A: ACTITUD FRENTE A EDAD ACTUAL SEGÚN COHORTE}

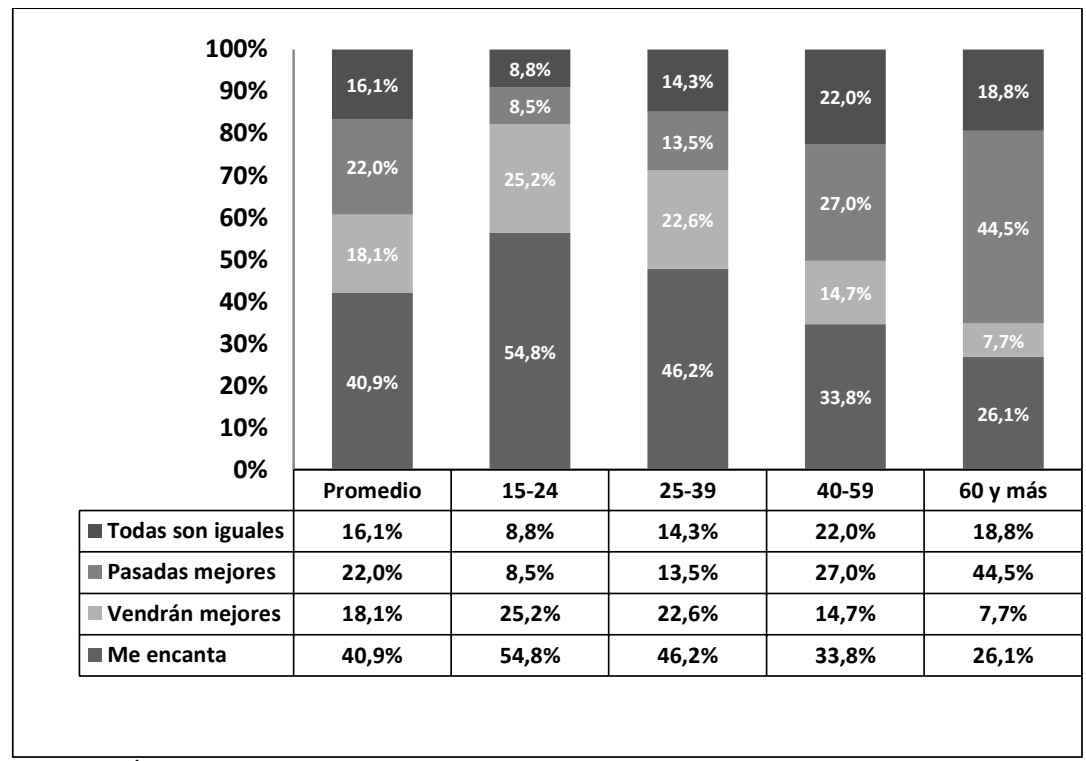

Fuente: Épocas y generaciones de chilenos. Fundación Visión Humana, Santiago, 2011. 
GRÁFICO 7B: ACTITUD FRENTE A EDAD ACTUAL SEGÚN GRUPOS SOCIOECONÓMICOS

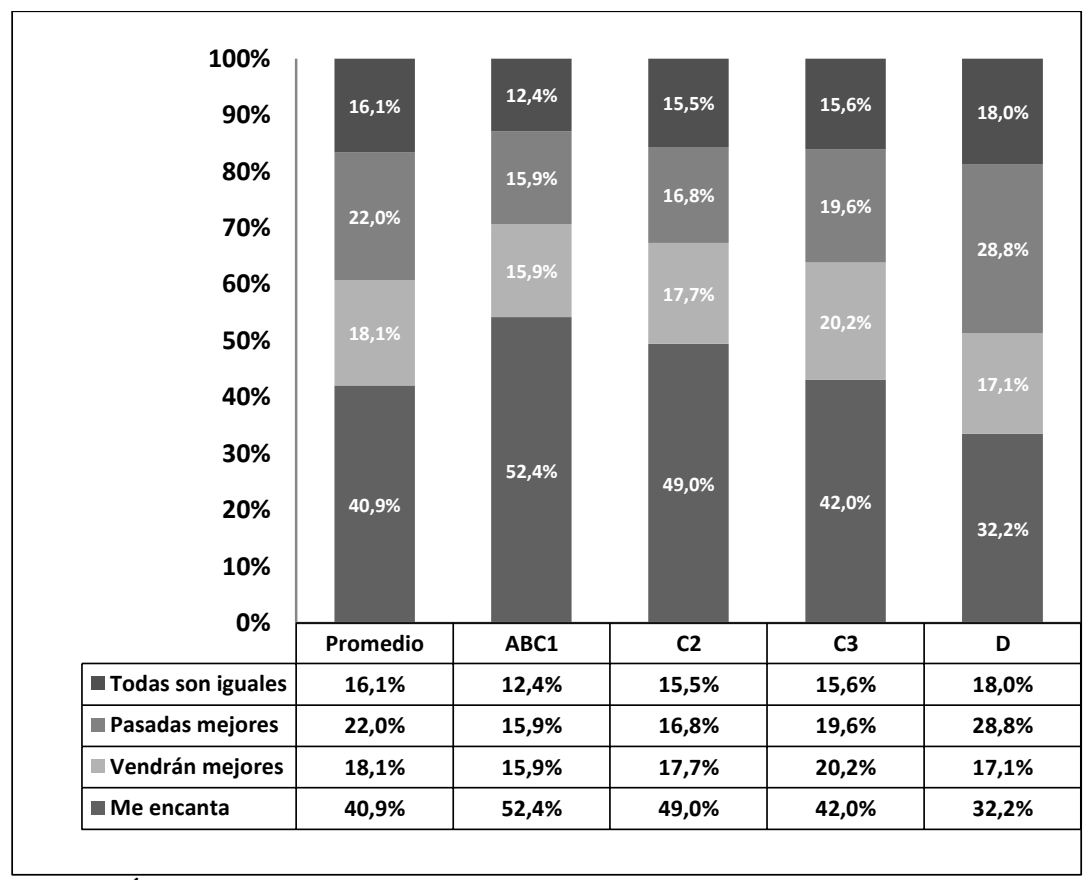

Fuente: Épocas y generaciones de chilenos. Fundación Visión Humana, Santiago, 2011.

Si se observa la distribución del conjunto, lo que predomina es el presente, acaso por su inmediatez subjetiva. Después de todo, es el único tiempo que se vive. Lo importante es que aquí aparecen diferencias fuertes, y comprensibles, según edad y clase. ${ }^{9}$ Entre los jóvenes se configura una actitud frente al tiempo que se concentra mayoritariamente entre la satisfacción con el presente y la expectativa sobre tiempos mejores. Entre los mayores se reduce el agrado con el presente y las expectativas de un mejor futuro, y se instala una clara tendencia a pensar que los tiempos pasados fueron mejores. Por su parte, los adul-

9 El factor territorial introduce. Mientras el norte minero parece agradado con su edad actual y presiente que las que vienen serán mejores, la provincia o agrópolis marca la igualdad de todas las fases. Acaso por la sabiduría de la provincia, que guarda memoria de la transición histórica completa. 
tos forman el grupo que vive su presente de la forma más ambigua o menos definida. Se equilibran entre el presente, el pasado y la indistinción entre fases de la vida. Futuro es lo que marcan, relativamente, menos. Se parecen así a los mayores en esto, como a los más jóvenes respecto al presente. Así, lo que los más jóvenes tienen de expectativa sobre el futuro y encanto con su actual edad, los mayores lo tienen de nostalgia sobre tiempos pasados. Acaso es la forma que asume la dinámica de las edades, que carga de presente y futuro a la juventud y de añoranza a los más adultos - algo que probablemente remita, según se verá luego, a su propia juventud-.

El factor de clase tiene efecto sólo en los extremos. Los grupos medio-altos se instalan en el presente, mientras los grupos bajos se cargan al pasado. Sin embargo, lo interesante en esta forma de relación con el tiempo se revela al juntar los efectos de edad y clase. El cruce sugiere que la particularidad de los jóvenes es que entre ellos se borra el peso que impone la condición de clase. Es la única cohorte en que aquel encanto con la edad actual o el anticipo de tiempos mejores no se ven afectados por la situación socioeconómica, probablemente por el hecho de no estar todavía plenamente inmersos en el mundo de la producción y el trabajo. Entre los adultos-jóvenes y los adultos, en cambio, que son los dos grupos en edades más propiamente «productivas», las diferencias de clase - que son, a fin de cuentas, diferencias de trabajo- se expresan también como actitudes respecto a su edad actual: en los estratos bajos se produce una separación respecto a la tendencia central de su cohorte, porque el tiempo presente no es de lo mejor ni crea agrado, y lo que es peor, tampoco parece haber esperanza de un mejor futuro.

\section{d) Décadas y generaciones}

Llegamos, por último, a la relación entre tiempo e identidad generacional. La pregunta de entrada es si cada uno se reconoce parte de una generación. Lo que se encuentra es una tendencia general y transversal a reconocerse completa o parcialmente como parte de una generación. ${ }^{10}$ Todos tienen una generación, pero no es la misma para todos. En esto no hay forma base, no inciden ni la clase social ni el territorio, solo contrastes generacionales. Cada cohorte se identifica con su(s)

10 Pocos se declaran fuera de alguna: 1 de cada 10, sin variables que hagan diferencia. 
década(s) de oro, y esa época coincide con la edad de juventud. ${ }^{11}$ Dicho de otro modo: la forma base es la identificación generacional con la fase/década de ingreso a la adultez o plenitud biográfico-social.

Es cierto que, como se ha indicado en análisis precedentes, se marcan todas las épocas que se viven, pero solo alguna(s) de ella(s) tiene(n) el privilegio de ser la década propia. Ocurriría como si las personas se identificaran con la década en que se hacían autónomos y comenzaban a ingresar y consolidarse en la vida social correspondiente. Se es de una década, o dos, aun cuando se pueda estar activo y actual en una fase extensa - desde los 15 hasta el final, con intensidad mayor entre los 20 y los 60 años-. Es como si el sujeto siguiera vigente, pero ya no como protagonista.

\section{CUADRO 1: IDENTIDAD Y DÉCADAS SEGÚN COHORTE}

\begin{tabular}{|l|c|c|c|c|c|c|c|c|}
\hline & $\begin{array}{c}\text { Los } \\
40\end{array}$ & $\begin{array}{c}\text { Los } \\
50\end{array}$ & $\begin{array}{c}\text { Los } \\
60\end{array}$ & $\begin{array}{c}\text { Los } \\
70\end{array}$ & $\begin{array}{c}\text { Los } \\
80\end{array}$ & $\begin{array}{c}\text { Los } \\
90\end{array}$ & $\begin{array}{c}\text { Los } \\
2000\end{array}$ & No sabe \\
\hline $15-24$ & 1,1 & 0,0 & 0,6 & 0,8 & 5,8 & 22,6 & 59,5 & 9,6 \\
\hline $25-39$ & 1,2 & 0,7 & 1,0 & 1,0 & 32,8 & 46,0 & 11,5 & 5,9 \\
\hline $40-59$ & 3,7 & 1,3 & 8,8 & 25,3 & 45,7 & 7,3 & 2,6 & 5,3 \\
\hline 60 y más & 5,9 & 13,9 & 37,0 & 24,2 & 8,1 & 0,7 & 1,5 & 8,8 \\
\hline
\end{tabular}

Fuente: Épocas y generaciones de chilenos. Fundación Visión Humana, Santiago, 2011.

El cuadro 1, a nuestro juicio, es una versión estilizada de todo lo dicho en los análisis previos. Las generaciones pueden comprenderse como encabalgamientos entre los tiempos biográficos y los tiempos sociales, de modo que las cohortes se suceden unas a otras, secuenciadas por el tiempo social y biográfico al mismo tiempo. Así puede verse el efecto «olas» o secuencialidad de las generaciones, en el sentido de unas que van entrando y otras que van saliendo del centro temporal de la vida y la sociedad. Ese proceso marca o identifica y, además, lo hace de modo

11 Lo mismo en el caso de alguna música y artistas que marcaron época: la identificación con unas u otras también es un asunto generacional. $\mathrm{Su}$ fuerza se nota, sobre todo, en los extremos: los mayores son de la época del mambo, el rock and roll, el twist; no así de la electrónica, el reggaetón o la nueva cumbia chilena. Y al revés ocurre lo mismo: los más jóvenes no se reconocen en la época de Arturo Gatica, Estela Rabal o Los Cinco Latinos. Caso especial es la alta identificación que produce la música de los sesenta/setenta aún en generaciones actualmente jóvenes, quizás por la trascendencia de esta época en la historia de la música. 
total y excluyente: es el caso que no hay ninguna otra variable, más que el año de los 18, o próximo, que incida en la identificación «decanal».

\section{CONCLUSIONES}

Queda enunciar algunos puntos que deja este estudio. Lo primero es que el análisis desde lo que aquí se ha definido como epocalidad de los sujetos - esto es, desde el reconocerse marcado por las formas elementales de una época- permite argumentar que solamente se marca lo vivido, todo lo vivido y sólo lo vivido. Los individuos marcan en todas las épocas que conocieron directamente y no marcan en ninguna que no hayan conocido vivencialmente. Es este orden que asume la relación entre tiempo e identidad el que permite entender que los mayores sean la única cohorte que se reconoce en todas las épocas y que a los jóvenes les sea imposible reconocerse en ninguno de los componentes de las décadas pasadas que no vivieron.

Ahora bien, la comparación por ámbitos sugiere que solo marcan en las épocas en que han vivido, en los ámbitos de la vida en los que ya estaban (en el caso de los más jóvenes) o todavía estaban (en el caso de los mayores) activados o actualizados. Como se señaló en su momento, los más jóvenes no participan de su época en trabajo y política porque su integración por estas vías aún no es plena. Y los mayores no participan ya de la época actual en sexualidad, tipos de familia y, cada vez menos, en tecnología, porque sus tiempos fueron los de antes.

De ese modo quedan conectadas la longevidad y longitud de épocas. El código será más extenso en la misma medida que el perfil-edad lo sea. Así, la forma del código de cualquier cohorte puede describirse según su longevidad, considerando, sin embargo, en los dos extremos, la deformación correspondiente.

- en el extremo anterior se produce una distorsión por entrada parcial de los más jóvenes;

- en el extremo posterior se produce una distorsión por salida parcial de los mayores.

De lo anterior se sigue que la epocalidad o condición de sentirse marcado por las épocas depende en gran medida de la fase biográfica en que se haya vivido cada etapa social. 
Fase 1: No activado, ni actualizado, en formación.

Fase 2: Plenamente actualizado.

Fase 3. No re-actualizándose progresivamente.

Por ahí se entiende la gravitación que tiene la etapa de juventud en la configuración de las distintas epocalidades y las diferencias intergeneracionales en lo que refiere, especialmente, a la sexualidad y la tecnología, por un lado, y al trabajo y la política, por el otro.

La cohorte, o la diacronía en la sincronía (las edades en el ahora) es la base también de la sincronía en la diacronía (la generación en los tiempos pasado, presente y por venir). Se articula así el recambio generacional con el paso del tiempo histórico. La sociedad sigue su camino de cambios, mientras los individuos van cursando sus distintas fases biográficas. Así, en cada época un grupo (cohorte) está saliendo, un grupo está entrando, y dos grupos están en medio y actuando. En un momento, durante veinte años, cada grupo está en la cresta de la ola, luego comienza a caer, y aparece otra, como una serie de curvas ondeantes en que al declinar de una le sigue el desarrollo de otras sin que nunca se detenga el proceso. Por eso cada generación se define también por su propia vivencia del tiempo o un reloj que es social y biológico al mismo tiempo: los mayores, a su juventud; los jóvenes, al presente y futuro.

El fenómeno generacional se revela, entonces, como el modo en que la sociedad humana hace su recambio de componentes individuales, articulando tiempos biográficos $-\mathrm{y}$ su secuencia de iniciomaduración-salida - con los tiempos sociales y su secuencia propia, la historia de una sociedad que, de este modo, «rueda». Es la condición de «gozne sobre el que se ejecuta el curso de la historia» que le atribuía Ortega y Gassett a las generaciones (Ortega y Gassett, 1983).

Ahora bien, siendo tan marcado y ordenado el ser epocal, generacional, histórico, ¿por qué no tiene la incidencia ideológica que parecen tener, por ejemplo, los grupos socioeconómicos? Todo el análisis precedente demuestra que la comunidad etario-histórica atraviesa clases, géneros, territorios, juntando y separando solo según los relojes de la historia y los biográficos de cada quien. Y esa comunidad tan densa y general, de la que prácticamente ningún individuo se escapa, así también entonces extensa como pocas, ¿por qué no se traduce, por ejemplo, en una ideología que vaya más allá de la propia autorreferencia vacía, aunque resonante, de un decirse de una época soy de los 80 o los 90 ? 
Acaso por dos razones. La primera es de complejidad: se trata de una filosofía de la historia, de un «relato» que sea encarnado por las generaciones. Esta alternativa, o es imposible (porque ¿quién entiende nuestras épocas?), o es trivializada a unos cuantos clichés o modas pasajeras que en realidad no alcanzan a hacer paisaje, o está hecha y es plana como una línea única y simple: línea continua de la modernización que arranca desde una tradición y avanza hacia una sociedad individuada-racionalizada. En ese paso, queda fuera todo pliegue local, toda «crónica».

La segunda refiere a la posibilidad de resonancias identitarias en las generaciones, de una identidad común generacional, que es uno de los tópicos más recurrentes en la discusión teórica sobre las generaciones. Los análisis muestran que la edad, como el género, une a lo que la estructura social básica separa. Reúne a ricos y pobres, muy educados y poco educados, y el caso es que, según esto demuestra, cuesta unirse orgánicamente lo que viene partido por la construcción socioeconómica. Así, las identidades de época o generación quedan como una identidad difícil, proyectos que nadie esta ideológicamente interesado en trabajar.

¿Qué hacer, entonces? La ciencia social podría intentar ahora sondear la experiencia épocal «cualitativa» de cada una de estas cohortes. Ya sabemos que existen y se reconocen. Falta ahora saberlas «aparte» y en sus propias lenguas. De ahí podrían desprenderse elementos para acompañar lo que la misma sociedad podría hacer fomentando el diálogo intergeneracional como historia viva y común, y no solo como cuestión de roles y fases biográficas.

SANTIAGO (CHILE), MARZO 2012

RECIBIDO, MARZO 2012

ACEPTADO, ABRIL 2012 


\section{REFERENCIAS BIBLIOGRÁFICAS}

HASTINGS, DONALD; LINDA BERRU y José RodRÍGUEZ (1978): «El análisis cohorte: su lógica y utilidad». Revista Mexicana de Sociología, Vol. 40, Número Extraordinario. México: Universidad Nacional Autónoma de México.

LECCARDI, CARMEN y CARLES FEIXA (2011): «El concepto de generación en las teorías sobre la juventud». Última Década №34. Valparaíso: Ediciones CIDPA.

MANNHEIM, KARL (1993): «El problema de las generaciones». Revista Española de Investigaciones Sociológicas (REIS) No62. Madrid: CIS.

ORTEGA Y GASSET, JOSÉ (1983): El tema de nuestro tiempo. Obras Completas, III. Madrid: Alianza.

SANCHÉZ DE LA YNCERA, IGNACIO (1993): «La sociología ante el problema generacional. Anotaciones al trabajo de Karl Mannheim». Revista Española de Investigaciones Sociológicas (REIS) $\mathrm{N}^{\circ} 62$. Madrid: CIS.

URIBE, ÓSCAR (1962): «Las edades y el cambio social». Revista Mexicana de Sociología, Vol. 24, №3. México: Universidad Nacional Autónoma de México. 